\title{
Cerebral venous air embolism during epidural injection in adult
}

\author{
Sharmili Sinha, Banambar Ray
}

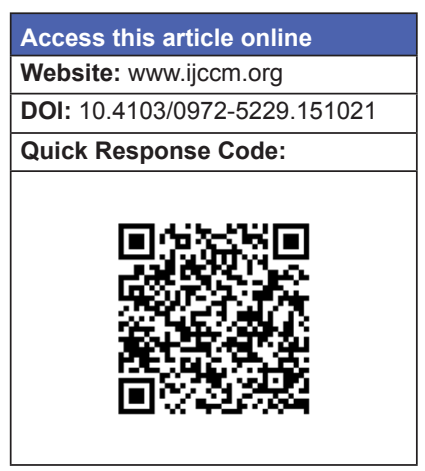

\section{Introduction}

Combined epidural and general anesthesia has been well accepted and widely practiced method of present day anesthesia for high risk cases as well as for postoperative analgesia. Use of epidural analgesia reduces requirement of intravenous (IV) analgesic drugs during surgery with greater hemodynamic stability. However, placement and maintenance of epidural catheter is always associated with risks of migration, bleeding, infection, air embolism and ineffective (patchy) analgesia, ${ }^{[1]}$ surgical emphysema, ${ }^{[2]}$ headache, ${ }^{[3]}$ leg pain. ${ }^{[4]}$

The epidural space is identified by loss of resistance technique using a saline or air filled syringe $(1 \mathrm{ml})$. Use of the air filled syringe $(1-1.5 \mathrm{ml})$ technique has been discouraged due to reports of air embolism ${ }^{[5-7]}$ and greater risk of patchy anesthesia.

During the postoperative period epidural catheter is used for continuous or intermittent analgesia. While

\section{From:}

Department of Critical Care Medicine, Apollo Hospitals, Bhubaneswar, Odisha, India

\section{Correspondence:}

Dr. Sharmili Sinha, Department of Critical Care Medicine, Apollo Hospitals, Bhubaneswar - 751 005, Odisha, India.

E-mail: sharmili.sinha@yahoo.co.in continuous slow infusion for local anesthesia solution from a closed system is unlikely to produce any air injection, intermittent injection can introduce air into the epidural space if adequate precautions are not taken.

\section{Case Report}

A 65-year-old lady with morbid obesity, hypertension, and rheumatoid arthritis was planned for total hip replacement under combined spinal and epidural anesthesia. Spinal anesthesia with $3 \mathrm{ml} 0.5 \%$ of bupivacaine and $25 \mathrm{mcg}$ of fentanyl was given at L3-4 interface with 26G Quinke's needle. Epidural space was identified at L2-3 level with a 18G Tuohy canula using loss of resistance technique with air $(1 \mathrm{ml})$. The air filled syringe was disconnected soon after the loss of resistance. A 20G epidural catheter was introduced and fixed at $12 \mathrm{~cm}$ at the skin level. 5 min after the test dose, infusion was established at $2 \mathrm{ml} / \mathrm{h}$ with bupivacaine $0.125 \%$ and fentanyl $(2 \mathrm{mcg} / \mathrm{ml})$. Surgery lasted for around $8 \mathrm{~h}$ and epidural infusion was stopped at $6 \mathrm{~h}$ of surgery due to hypotension mostly due to bleeding $(1100 \mathrm{ml})$. It was managed with fluids and blood transfusion through a peripheral cannula. In Intensive Care Unit for severe pain, she was prescribed an epidural bolus of $10 \mathrm{ml}$ of $0.125 \%$ bupivacaine with $20 \mathrm{mcg}$ of fentanyl along with IV tramadol $50 \mathrm{mg}$ and promethazine $12.5 \mathrm{mg}$. With a lot of 
resistance, only $8 \mathrm{ml}$ of the mixture could be injected over around $2 \mathrm{~min}$. There was sudden bradycardia $(73 / \mathrm{min})$ and hypotension (systolic pressure $86 \mathrm{mmHg}$ ). She started jerking and gasping with suddenly diminished level of consciousness. Blood sugar was $242 \mathrm{mg} \%$ (13.44 mmol). Left pupil was noticed to be dilated and fixed. She was resuscitated with fluids and low dose noradrenaline and intubated.

An urgent computed tomography (CT) brain was done, which revealed air around the brain stem and no bleeding. Within $1 \mathrm{~h}$ she was awake but left pupil still remained dilated and fixed. She was extubated the next day. The mildly altered sensorium lasted for 2 days.

\section{Discussion}

The differential diagnoses for the sudden changes included venous air embolism, total spinal anesthesia and bupivacaine toxicity. Bupivacaine toxicity was ruled out as it was used during surgery with no complications, and quick stabilization of hemodynamics disproves it also. The possibility of total spinal anesthesia was excluded on the basis of unequal pupil, quick recovery of hemodynamics and sensorium and no residual limb weakness. With the presence of a pneumoencephalus, the cause of sudden deterioration was most likely due to cerebral venous air embolism. Magnetic resonance imaging for locating catheter tip could not be done due to the presence of the implant. Transesophageal echocardiography or gas analyzer was not available in the acute situation for detecting intra-cardiac air or analyzing nitrogen in expired gas to look for air in circulation.

It is possible that there was epidural catheter migration or coiling during re-positioning after surgery. This caused increased resistance for injection resulting in epidural venous plexus injury. The source of air in the epidural space at this point could be either from use of the air filled syringe or left over air in the catheter or syringe. This air could have entered the injured venous plexus resulting in symptomatic venous air embolism. There was no central venous catheter to check for venous air. An acute intracerebral event was highly suspected for which a CT scan was performed. Presence of the pneumoencephalus [Figures 1 and 2] suggested cerebral venous air embolism. In obese patients, intra thoracic and abdominal pressures are higher than the general population. This can lead to an engorged epidural venous plexus, which is vulnerable to injury due to migration of the catheter or higher pressure of injections.

Usubiagahas demonstrated that even slow injection of anesthetic solutions can raise the pressure from
10 to $60 \mathrm{~cm} \mathrm{H}_{2} \mathrm{O} \cdot{ }^{[7]}$ Hence, the peak pressure will be much higher with forceful injection as in this case. This could have created a hole in the veins and air could have easily entered.

Naulty et al. detected venous air emboli in healthy primipara in $43 \%$ cases using an ultrasonic Doppler transducer after epidural catheter placement using loss of resistance technique using air. ${ }^{[8]}$ This supports our presumption of a small amount of preexisting air in the space during insertion.

In Naulty et al.'s study, there was a relation between fasting hours and occurrence of air embolism. ${ }^{[8]}$ In our case, there was low intake status for days with a prolonged fasting period of $11 \mathrm{~h}$. This could have created a low central venous pressure and low epidural venous pressure, and the epidural veins may have become vulnerable for air embolism during forceful injection. Bromage has suggested that during left lateral position, epidural pressure is further reduced and may become subatmospheric. ${ }^{[9]}$ So if an epidural vein ruptures, air embolism can occur even during hanging drop testing.

Distorted anatomy of the spine due to arthritic changes or surgery can create venous malformation with noncollapsible side wall. This predisposes to venous plexus injury and increases chances of air embolism. ${ }^{[10]}$ Our case had long-standing rheumatoid arthritis. Air embolism has been described during identification of the epidural space in children in the operation theatre. ${ }^{[5,6,11]}$ In all previous reports, no imaging was performed under such circumstances. We could conduct a CT scan which established the diagnosis of cerebral venous air embolism. The patency of the epidural catheter should always be confirmed before any injection especially after any position change and injections should

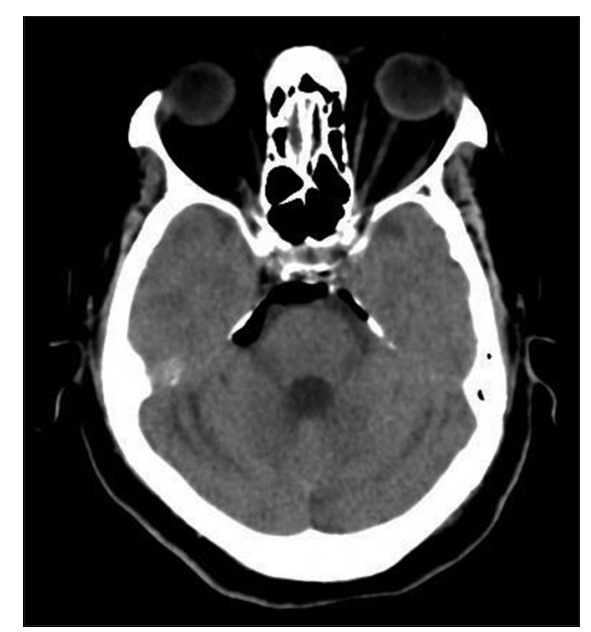

Figure I: Computed tomography image of intra-cranial air around upper part of brain stem 


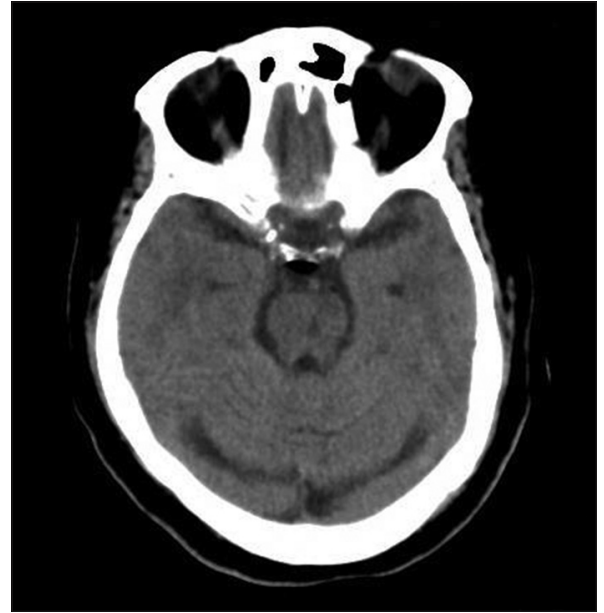

Figure 2: Computed tomography image of intra-cranial air around lower part of brain stem

be withheld if necessary. Only trained personnel should be allowed to handle epidural catheter.

\section{References}

1. Dalens B, Bazin JE, Haberer JP. Epidural bubbles as a cause of incomplete analgesia during epidural anesthesia. Anesth Analg 1987;66:679-83
2. Carter MI. Cervical surgical emphysema following extradural analgesia. Anaesthesia 1984;39:1115-6.

3. Hogan QH, Haddox JD. Headache from intracranial air after a lumbar epidural injection: Subarachnoid or subdural? Reg Anesth 1992;17:303-5.

4. Kennedy TM, Ullman DA, Harte FA, Saberski LR, Greenhouse BB Lumbar root compression secondary to epidural air. Anesth Analg 1988;67:1184-6.

5. Schwartz N, Eisenkraft JB. Probable venous air embolism during epidural placement in an infant. Anesth Analg 1993;76:1136-8.

6. Guinard JP, Borboen M. Probable venous air embolism during caudal anesthesia in a child. Anesth Analg 1993;76:1134-5.

7. Usubiaga JE, Wikinski JA, Usubiaga LE. Epidural pressure and it relation to spread of anesthetic solutions in epidural space. Anesth Analg 1967;46:440-6.

8. Naulty JS, Ostheimer GW, Datta S, Knapp R, Weiss JB. Incidence of venous air embolism during epidural catheter insertion. Anesthesiology 1982;57:410-2.

9. Bromage PR. Identification of the epidural space, Epidural Analgesia. Philadelphia: WB Saunders; 1978. p. 187.

10. Jackson KE, Rauck RL. Suspected venous air embolism during epidural anesthesia. Anesthesiology 1991;74:190-1.

11. Sethna NF, Berde CB. Venous air embolism during identification of the epidural space in children. Anesth Analg 1993;76:925-7.

How to cite this article: Sinha S, Ray B. Cerebral venous air embolism during epidural injection in adult. Indian J Crit Care Med 2015;19:116-8.

Source of Support: Nil, Conflict of Interest: None declared. 